\title{
Low-Energy Plasma Focus Device as an Electron Beam Source
}

\author{
Muhammad Zubair Khan, ${ }^{1,2}$ Yap Seong Ling, ${ }^{1}$ Ibrar Yaqoob, ${ }^{3}$ Nitturi Naresh Kumar, \\ Lim Lian Kuang, ${ }^{1}$ and Wong Chiow San ${ }^{1}$ \\ ${ }^{1}$ Plasma Technology Research Center, Department of Physics, Faculty of Science, University of Malaya, 50603 Kuala Lumpur, Malaysia \\ ${ }^{2}$ Department of Physics, Federal Urdu University of Arts, Science \& Technology, 45320 Islamabad, Pakistan \\ ${ }^{3}$ Faculty of Computer Science and Information Technology, University of Malaya, 50603 Kuala Lumpur, Malaysia
}

Correspondence should be addressed to Muhammad Zubair Khan; mzubairkhan_um76@yahoo.com

Received 24 March 2014; Revised 17 June 2014; Accepted 18 June 2014; Published 21 July 2014

Academic Editor: Constantin Kappas

Copyright (C) 2014 Muhammad Zubair Khan et al. This is an open access article distributed under the Creative Commons Attribution License, which permits unrestricted use, distribution, and reproduction in any medium, provided the original work is properly cited.

\begin{abstract}
A low-energy plasma focus device was used as an electron beam source. A technique was developed to simultaneously measure the electron beam intensity and energy. The system was operated in Argon filling at an optimum pressure of 1.7 mbar. A Faraday cup was used together with an array of filtered PIN diodes. The beam-target X-rays were registered through X-ray spectrometry. Copper and lead line radiations were registered upon usage as targets. The maximum electron beam charge and density were estimated to be $0.31 \mu \mathrm{C}$ and $13.5 \times 10^{16} / \mathrm{m}^{3}$, respectively. The average energy of the electron beam was $500 \mathrm{keV}$. The high flux of the electron beam can be potentially applicable in material sciences.
\end{abstract}

\section{Introduction}

Dense plasma focus (DPF) is potential candidate for various technological applications. The emission characteristics of electron beams and X-rays, as well as the correlation of the electron and X-ray pulses with other PF phenomena, have been previously reported [1-5]. Pulsed electron beams and $\mathrm{X}$-rays should be analyzed to explore possible applicationoriented studies and elucidate the physical phenomena responsible for the generation and acceleration of charged particles and the emission of electromagnetic radiation pulses. Several studies have focused on the physical mechanisms of the generation of electron beams by correlations [6] with HXR emission [7], ion beam [8], neutron [9], and electrical measurements [10].

Tartari et al. [11] proposed X-ray brachytherapy sources based on the interactions of the relativistic electron beam of DPF with a high- $Z$ target. The electron beam energy was distributed from nearly $20 \mathrm{keV}$ to $500 \mathrm{keV}$ using a magnetic spectrometer [12]. Tartari et al. [13] measured the X-ray spectra in a $7 \mathrm{~kJ}$ DPF device and hypothesized that the electron beam responsible for $\mathrm{X}$-ray production comprised relativistic electron beams and electrode components with energies of about $30-45 \mathrm{keV}$. Time-resolved studies of electron beam emission were carried out using different detectors, such as Cherenkov detector [14], Rogowski coil [15], Faraday cup [16-18], and magnetic energy analyzer [19]. Faraday cup is a cost-effective and simple detector that exhibits fast signal processing and particle detection with an energy range of a few $\mathrm{keV}$ to hundreds of $\mathrm{keV}$.

This study aimed to explore the use of low-energy plasma focus devices as sources of electron beam. These devices were characterized by high electron beam energy and high flux, which could be beneficial for applications in material sciences. Analysis of the X-ray spectra with lead target revealed the marked effects of electron beams in our plasma focus device.

\section{Experimental Setup}

Experimental measurements were carried out on a Mathertype plasma focus device. This device was energized by a $30 \mu \mathrm{F}$ Maxwell capacitor, which was charged up to $12 \mathrm{kV}$ with a lead target. Lead material with diameter and width of $1.5 \mathrm{~cm}$ and $0.35 \mathrm{~cm}$, respectively, was used. The calculated 


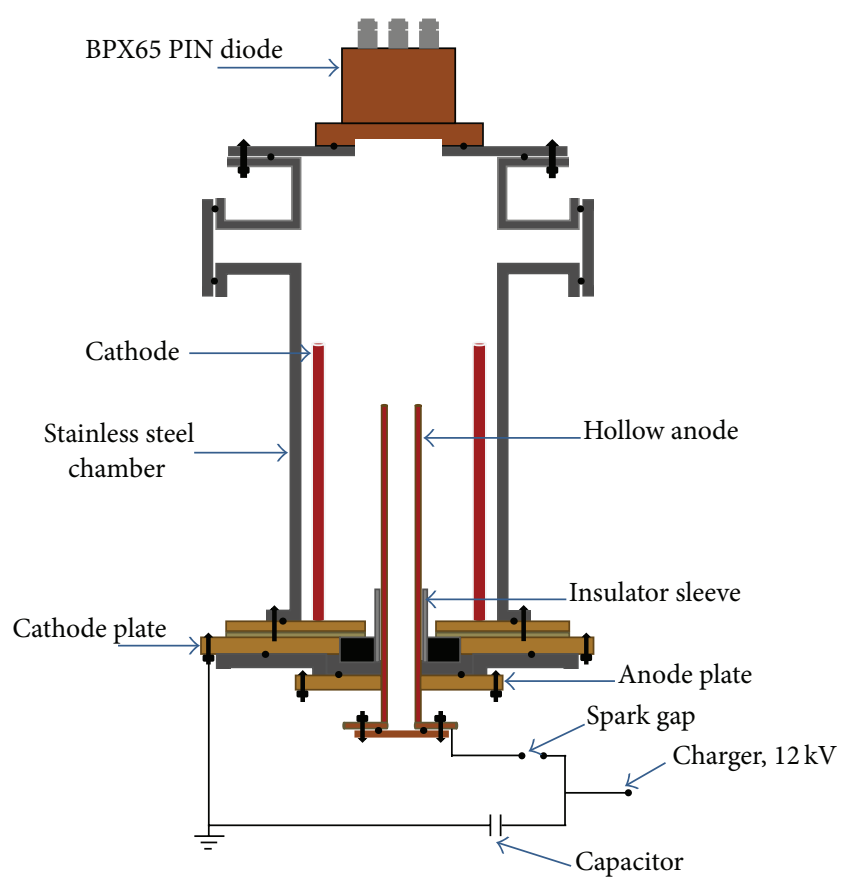

FIGURE 1: Schematic of plasma focus device.

total external inductance was found to be $165 \mathrm{nH}$. Figure 1 shows the diagram of a $2.2 \mathrm{~kJ}$ plasma focus device.

The discharge tube comprised copper electrodes, in which the inner electrode exhibited a hollow cylindrical form and served as an anode with diameter and effective length of $1.9 \mathrm{~cm}$ and $18 \mathrm{~cm}$, respectively. Hollow anodes were used considering previous studies on energetic electron beams in plasma focus devices. The outer electrode consisted of six copper rods in the form of a squirrel cage with an inner diameter of $3.2 \mathrm{~cm}$. The length of the individual cathode rod was $27 \mathrm{~cm}$, which was $9 \mathrm{~cm}$ higher than that of the anode rod. Pyrex glasses were used as insulators to separate the hollow anode and cathode. The vacuum system comprised a rotary vane pump and an evacuated chamber with a pressure lower than $10^{-2}$ mbar, which was sufficient for experimentations. The chamber was refreshed after every shot to reduce gas contamination with impurities on the output radiation. Fresh Argon gas was refilled to a desired pressure.

Identical coaxial cables (length, $110 \mathrm{~cm}$ ) were used for all electrical diagnostics. All coaxial cables were protected with aluminum foils to reduce the effects of electromagnetic noises on data signals. Two DPO4043 digital storage oscilloscopes were used to record all electrical signals from the Rogowski coil, high-voltage probe, five-channel PIN diode, and energetic electron beams through the Faraday cup. The oscilloscope was simultaneously triggered for all electrical signals.

Five-channel PIN diodes were normalized against each other by masking with identical foils of aluminized Mylar (thickness, $23 \mu \mathrm{m}$ ). The PIN diode response ranged between $1 \mathrm{keV}$ and $30 \mathrm{keV}$. Filter combinations were used to verify the variations in the spectral window.

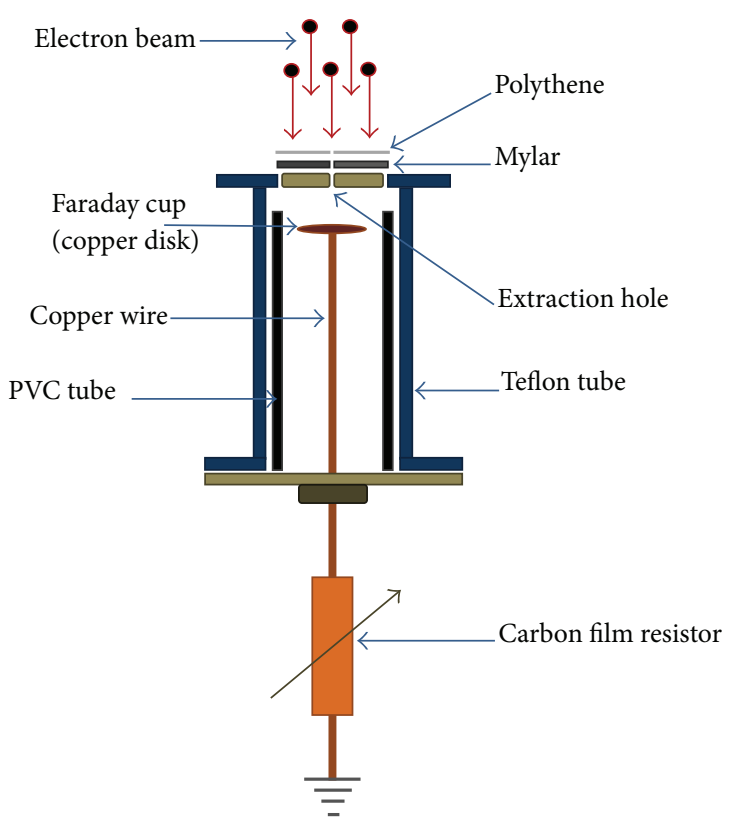

FIGURE 2: Schematic of Faraday cup.

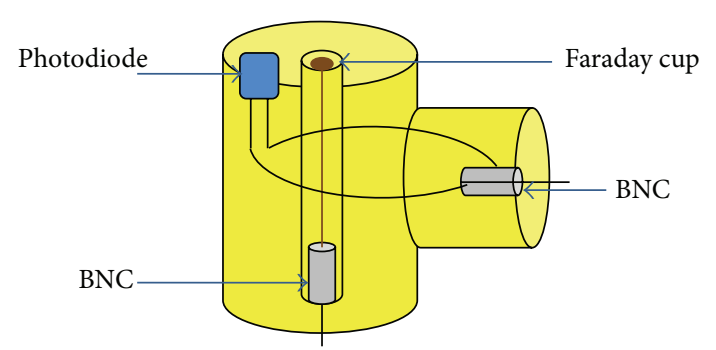

FIGURE 3: Schematic of arrangement of Faraday cup with photodiode.

The Faraday cup contained a metallic disk that served as a charge collector and developed in bias mode with a resistance of $0.1 \Omega$, which was prepared with a parallel combination of 10 carbon film resistors (resistance, $1 \Omega$ ). The Faraday cup comprised a flat circular copper disk (diameter, $7.5 \mathrm{~mm}$ ) placed inside a Teflon insulator tube, which was then enclosed in the PVC pipe (Figure 2).

A small extraction hole (diameter, $3 \mathrm{~mm}$ ) was placed in front of the disk covered with Mylar and polythene sheet to allow only the axial movement of energetic electrons that hit the copper disk and reduce the effects of high potential and radiation on the signals of the energetic electron beam before and after plasma focus. The diameter of the Faraday cup was restricted by the diameter of the PVC insulator tube, which was used inside the hollow anode. The energetic electron beam was detected by placing the Faraday cup at the bottom end of the hollow anode at a distance of $37 \mathrm{~cm}$ from the anode tip.

A photodiode (BPX65) was used with the Faraday cup at the same position and distance from the top end of the hollow anode (Figure 3). 


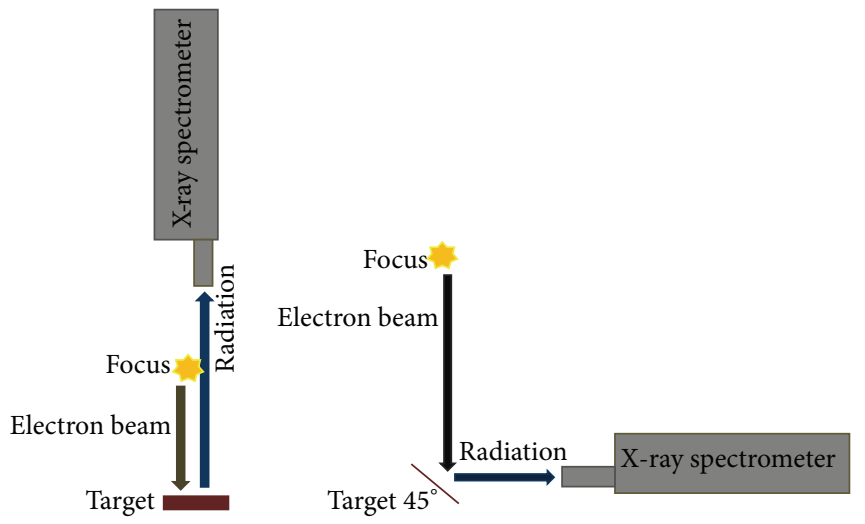

(a) Top-on of system

(b) Side-on of system

FIGURE 4: X-ray spectrometer position at top-on of system with target (a) and side-on of system with target at an angle of 45 degrees (b).

TABLE 1: Design parameters of plasma focus system.

\begin{tabular}{lccc}
\hline Component & Length $(\mathrm{cm})$ & Diameter $(\mathrm{cm})$ & Material \\
\hline Hollow anode & 18.00 & $1.90 / 1.60($ O.D/I.D) & Copper \\
Cathode rod & 27.20 & 0.95 & Copper \\
Insulator sleeve & 5.00 & 2.00 & Pyrex \\
Faraday cup plate & 0.1 & 0.75 & Copper \\
Photodiode (BPX65) & - & - & - \\
\hline
\end{tabular}

We proposed a technique to identify the emissions from the electron beam with photoemissions before and after focusing from the focus region.

An XR100CR X-ray spectrometer was used at the top and side of the system to record the X-ray line spectra caused by the electron beam-lead target collision (Figure 4).

This spectrometer was suitable for analyzing X-ray energy distribution and was sensitive up to $45 \mathrm{keV}$ energy.

\section{Results and Discussion}

We analyzed the electron beam emissions from the lowenergy plasma focus device to demonstrate that the charged particles are normally emitted from the plasma column. The directions of the emission of ions and electrons are opposite each other and directed toward the anode for the electrons. The emitted electron beams exhibit energies ranging from few $\mathrm{keV}$ to hundreds of $\mathrm{keV}[20,21]$.

To assess the use of low-energy plasma focus devices as electron beam sources, various parameters were analyzed with respect to the filling pressure of the Argon gas. X-ray emissions from Argon-operated plasma focus were investigated by time-resolved PIN diode detectors. Table 1 lists the design parameters of the plasma focus device.

An array of filtered five-channel PIN diodes was housed at a distance of $43.50 \mathrm{~cm}$ from the head of the hollow anode to detect X-rays and measure the radiation emission from the plasma focus. The glass window of the PIN diode was covered with Al foils with specific thicknesses (Table 2) and was
TABLe 2: An array of five PIN diodes exposed with $\mathrm{Al}$ foil plus aluminized Mylar $(\mu \mathrm{m})$.

\begin{tabular}{lcc}
\hline PIN diode & Filter & Thickness $(\mu \mathrm{m})$ \\
\hline 1 & Aluminized Mylar & 23 \\
2 & $\mathrm{Al}+$ aluminized Mylar & $23+20$ \\
3 & $\mathrm{Al}+$ aluminized Mylar & $23+30$ \\
4 & $\mathrm{Al}+$ aluminized Mylar & $23+40$ \\
5 & $\mathrm{Al}+$ aluminized Mylar & $23+100$ \\
\hline
\end{tabular}

detached to detect X-ray emissions. The PIN diode response ranged from $0.5 \mathrm{keV}$ to $30 \mathrm{keV}$ [22].

Figure 5 illustrates the transmission curves of the BPX65 diode that was attached with absorption filters.

The X-ray yield in $4 \pi$-geometry and the system efficiency of X-ray emission could be calculated from five-channel PIN diodes that were masked with $\mathrm{Al}$ foils. The X-ray yield was calculated as follows [23-25]:

$$
Y=\frac{Q_{\exp }(4 \pi)}{d \Omega S(E) T(E)},
$$

where

$$
Q_{\exp }=\int \frac{V d t}{R}(\mathrm{C})
$$

$\int V d t$ represents the area under the curve with the filter of the PIN diode, $R=50 \Omega, S(E)$ is the average sensitivity of the detector, and $T(E)$ is the average filter transmission. $d \Omega=d A / r_{o}^{2}$ (sr.) is the solid angle subtended by the detector at the anode center, where $d A=\pi r^{2}, r$ is the radius of the exposed area of one detector, and $r_{o}$ is the distance between the detector and hollow anode.

The results were discussed in three parts as follows.

(1) Result with Five-Channel PIN Diode. The variations in Xray emissions as functions of the Argon gas pressure possess efficient functions in generating radiation in the plasma focus device. In our experiment, a pair of Ross filters $(20 \mu \mathrm{m}$ Al foil, $100 \mu \mathrm{m} \mathrm{Al}$ foil; $30 \mu \mathrm{m} \mathrm{Al} \mathrm{foil,} 100 \mu \mathrm{m} \mathrm{Al} \mathrm{foil;} \mathrm{and} 40 \mu \mathrm{m} \mathrm{Al}$ 


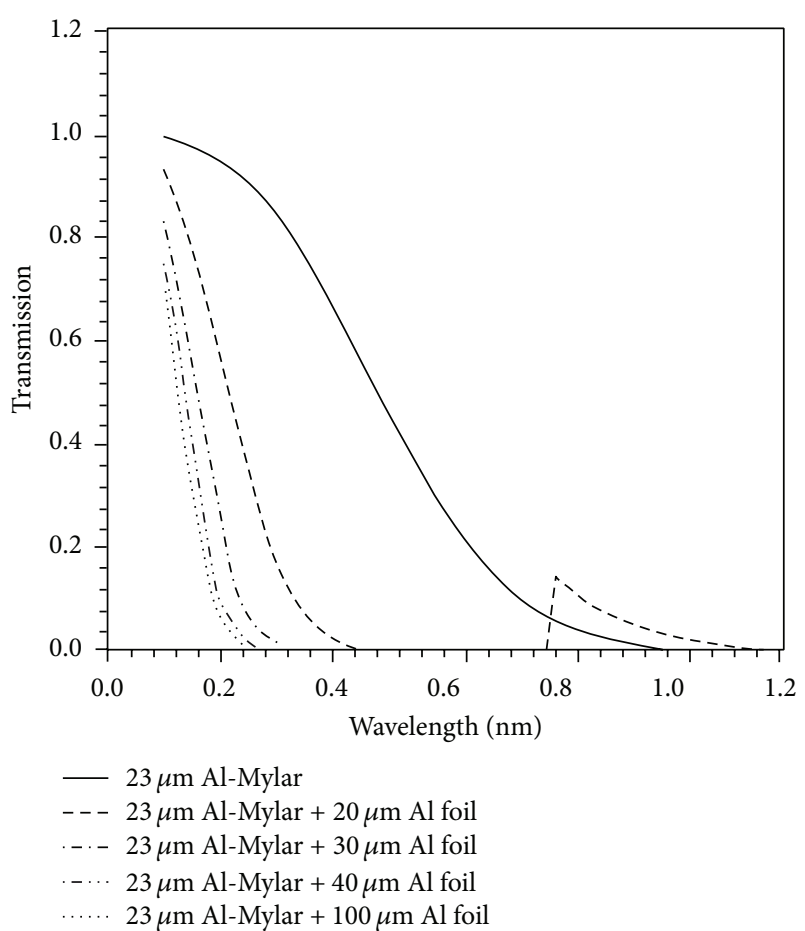

Figure 5: Transmission curves of $23 \mu \mathrm{m}$ aluminized Mylar, $23 \mu \mathrm{m}$ aluminized Mylar $+(20 \mu \mathrm{m}, 30 \mu \mathrm{m}, 40 \mu \mathrm{m}$, and $100 \mu \mathrm{m}) \mathrm{Al}$ foil.

foil, $100 \mu \mathrm{m}$ Al foil) were used to determine the X-ray yield. Figure 6 shows the variations of the average signal intensity with different Argon gas pressures.

The maximum average signal intensities were recorded with $20 \mu \mathrm{m}, 30 \mu \mathrm{m}$, and $40 \mu \mathrm{m} \mathrm{Al} \mathrm{foil} \mathrm{at} \mathrm{an} \mathrm{Argon} \mathrm{gas} \mathrm{pressure}$ of 1.7 mbar.

The variations in the total X-ray yield and efficiency against Argon gas pressures at a constant applied voltage of $12 \mathrm{kV}$ are shown in Figure 7.

The maximum total X-ray yields were $77 \mathrm{~mJ}, 47 \mathrm{~mJ}$, and $42 \mathrm{~mJ}$ with corresponding efficiencies of $0.0035 \%, 0.0021 \%$, and $0.0018 \%$, respectively, in $4 \pi$-geometry at an optimum pressure of 1.7 mbar. After a series of experiments, we obtained maximum X-ray yield at a pressure of $1.7 \mathrm{mbar}$ at a constant voltage of $12 \mathrm{kV}$ by using pairs of $\mathrm{Al}$ foils with specific thicknesses ( $20 \mu \mathrm{m} \mathrm{Al}$ foil, $100 \mu \mathrm{m} \mathrm{Al}$ foil; $30 \mu \mathrm{m} \mathrm{Al}$ foil, $100 \mu \mathrm{m} \mathrm{Al}$ foil; and $40 \mu \mathrm{m} \mathrm{Al}$ foil, $100 \mu \mathrm{m} \mathrm{Al}$ foil). These foils were fixed on top of the hollow anode tip at a distance of $43.50 \mathrm{~cm}$. The energetic electron beam interacted with the lead target, which was placed at a depth of $27 \mathrm{~cm}$ in the hollow anode.

The results revealed that the maximum total $\mathrm{X}$-ray yields were $77 \mathrm{~mJ}, 47 \mathrm{~mJ}$, and $42 \mathrm{~mJ}$ at an Argon gas pressure of 1.7 mbar by using pairs of $\mathrm{Al}$ foils with respective thicknesses of $20 \mu \mathrm{m}$ and $100 \mu \mathrm{m}, 30 \mu \mathrm{m}$ and $100 \mu \mathrm{m}$, and $40 \mu \mathrm{m}$ and $100 \mu \mathrm{m}$. The results from our low-energy plasma focus device were significant. The radiated energy depended on the filling pressure and the shape of the hollow anode because of the strong electron beam-hollow anode interactions. The Xray yield decreased for pressures higher or lower than the

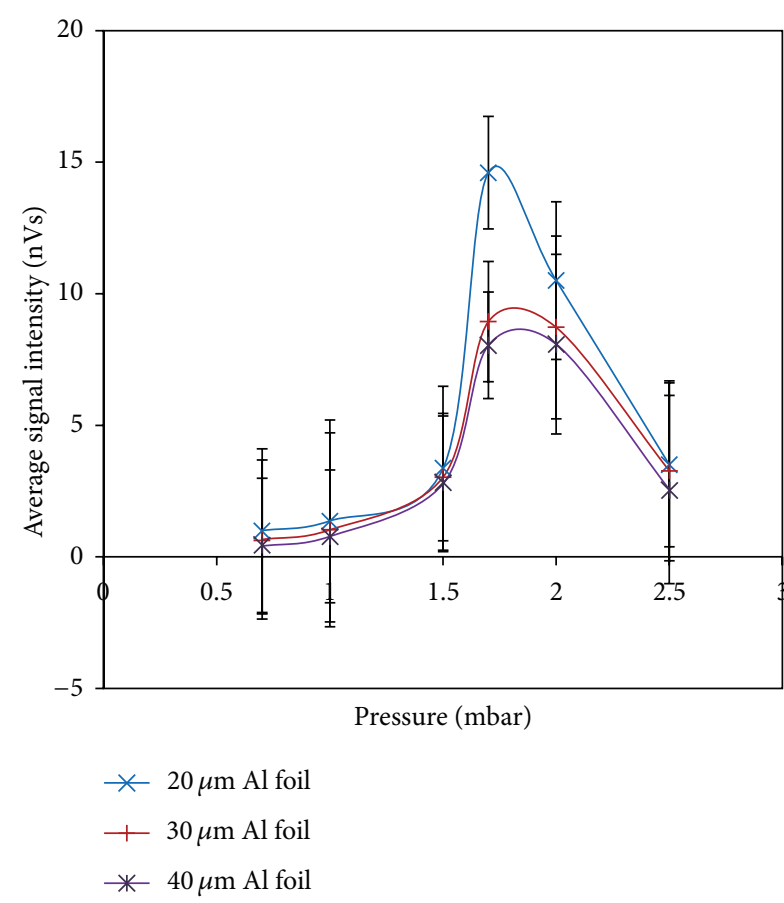

FIGURE 6: Variation of average signal intensity recorded by $\mathrm{Al}$ foil $(20 \mu \mathrm{m}, 30 \mu \mathrm{m}$, and $40 \mu \mathrm{m})$ versus Argon gas pressure.

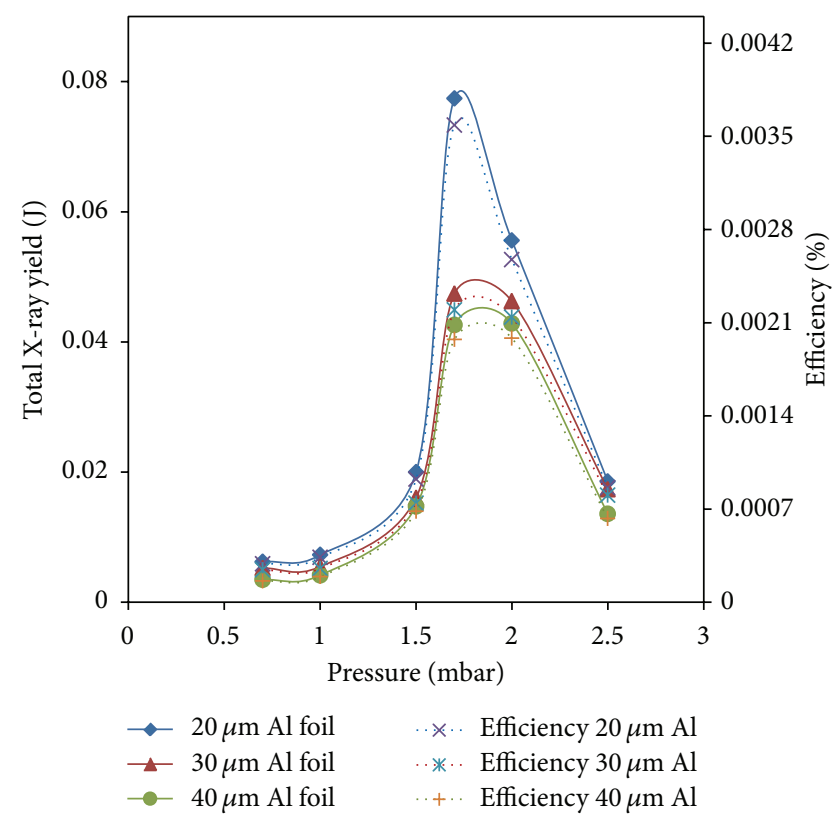

FIgURE 7: Variation of total X-ray yield in $4 \pi$-geometry with efficiency versus Argon gas pressure at constant applied voltage $12 \mathrm{kV}$.

optimum Argon pressure (1.7 mbar). The X-ray yield could be enhanced by reducing the system inductance, system size, and factors related to the electron beam-hollow anode interactions. The X-ray yield was high in the Argon pressure range of $1.5 \mathrm{mbar}$ to $2.0 \mathrm{mbar}$; therefore, the intensity of 

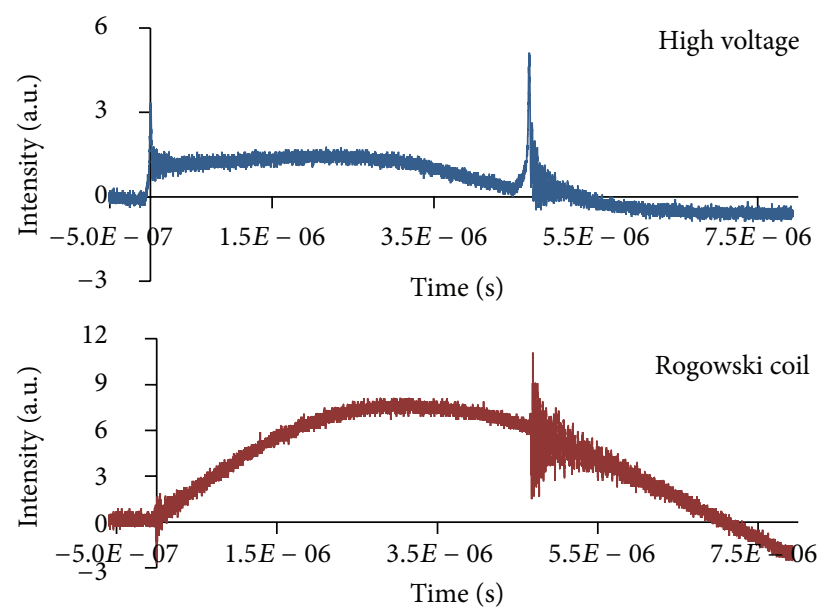

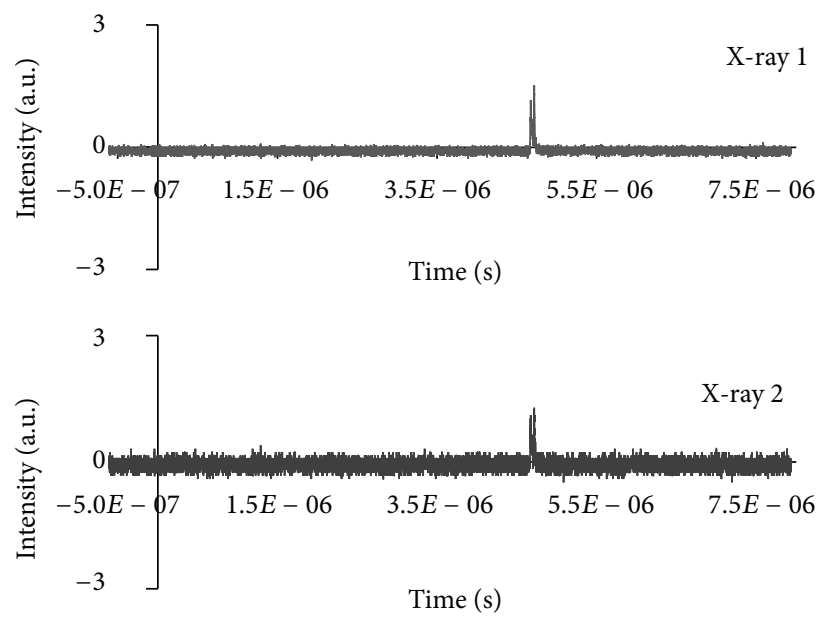

(a)

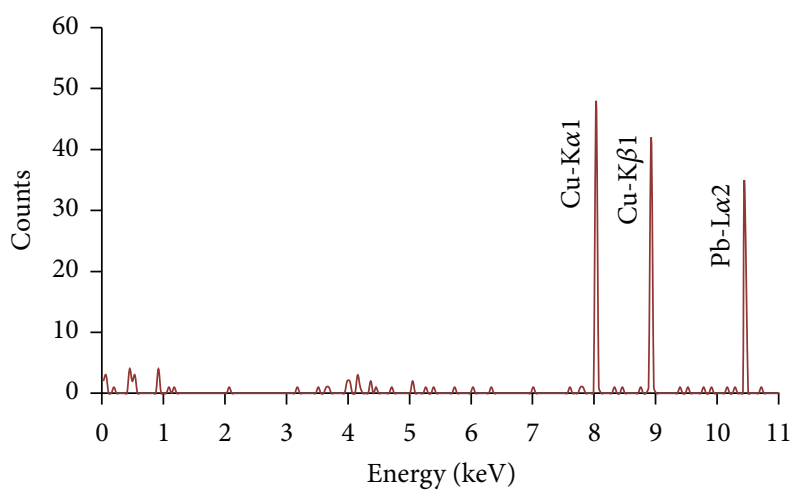

(b)

Figure 8: (a) Temporal evolution of X-ray pulses with $\mathrm{Al}$ foil thickness for pressure $1.7 \mathrm{mbar}$, X-ray 1 ( $23 \mu \mathrm{m}$ aluminized Mylar plus $30 \mu \mathrm{m}$ Al foil) and X-ray $2(23 \mu \mathrm{m}$ aluminized Mylar plus $20 \mu \mathrm{m}$ Al foil) with typical high voltage and Rogowski coil signal. (b) X-ray spectrum: X-ray produced by energetic electron beam-target effect at an angle of $45^{\circ}$ when the spectrometer is at side-on position.

the electron beam was high in this range for potential applications in analysis of material characteristics.

(2) Results with X-Ray Spectrometer. The X-ray spectrometer was used to trace the $\mathrm{X}$-ray line spectra and analyze the X-ray energy spectrum within $45 \mathrm{keV}$. In the first experiment, this spectrometer was used at side-on position below the system (distance from focus region, $37 \mathrm{~cm}$; distance from the lead target, $4 \mathrm{~cm}$; and angle, $45^{\circ}$ ). The X-ray line spectra show energies of $8.07 \mathrm{keV}, 8.67 \mathrm{keV}$, and $10.42 \mathrm{keV}$, which correspond to $\mathrm{Cu}-\mathrm{K}_{\alpha 1}, \mathrm{Cu}-\mathrm{K}_{\beta 1}$, and $\mathrm{Pb}-\mathrm{L}_{\alpha 2}$ lines with temporal evolution of $\mathrm{X}$-ray pulses at specific $\mathrm{Al}$ foil thickness and Argon pressure of $1.7 \mathrm{mbar}$. X-ray 1 ( $23 \mu \mathrm{m}$ aluminized Mylar plus $30 \mu \mathrm{m}$ Al foil $)$ and X-ray $2(23 \mu \mathrm{m}$ aluminized Mylar plus $20 \mu \mathrm{m} \mathrm{Al}$ foil) were used with signals from the high-voltage probe and Rogowski coil (Figure 8).

For the second experiment, the X-ray spectrometer was used at the top-on position of the system at a distance of $47.50 \mathrm{~cm}$ from the lead target within the hollow anode. The $\mathrm{X}$-ray line spectra reveal energies of $8.80 \mathrm{keV}$ and $10.46 \mathrm{keV}$, which correspond to $\mathrm{Cu}-\mathrm{K}_{\beta 1}$ and $\mathrm{Pb}-\mathrm{L}_{\alpha 2}$ lines with temporal evolution of X-ray pulses with specific $\mathrm{Al}$ foil thickness and Argon pressure of $1.7 \mathrm{mbar}$. X-ray 1 ( $23 \mu \mathrm{m}$ aluminized Mylar plus $30 \mu \mathrm{m}$ Al foil) and X-ray $2(23 \mu \mathrm{m}$ aluminized Mylar plus $20 \mu \mathrm{m} \mathrm{Al}$ foil) were used with signals from the high-voltage probe and Rogowski coil (Figure 9).

Spectrometer results indicated the presence of an energetic electron beam emitted from the focus region because of the instabilities that occur upon hitting the target material. The energy of the energetic electron beam was high enough to produce $\mathrm{Pb}-\mathrm{K}_{\alpha 1}(74 \mathrm{keV})$ line radiation in the $\mathrm{X}$-ray line spectra. However, this radiation was impossible to be detected by our spectrometer because of its constraints in the energy range.

(3) Results with Self-Biased Faraday Cup. In this experiment, the Faraday cup and photodiode were employed and uniquely arranged to determine the temporal behavior of the emissions from the electron beam and photoemissions from the plasma focus. Signals from the electron beam, photoemission, highvoltage probe, and Rogowski coil for a shot at a pressure of 1.7 mbar are shown in Figure 10. The electron beam current 

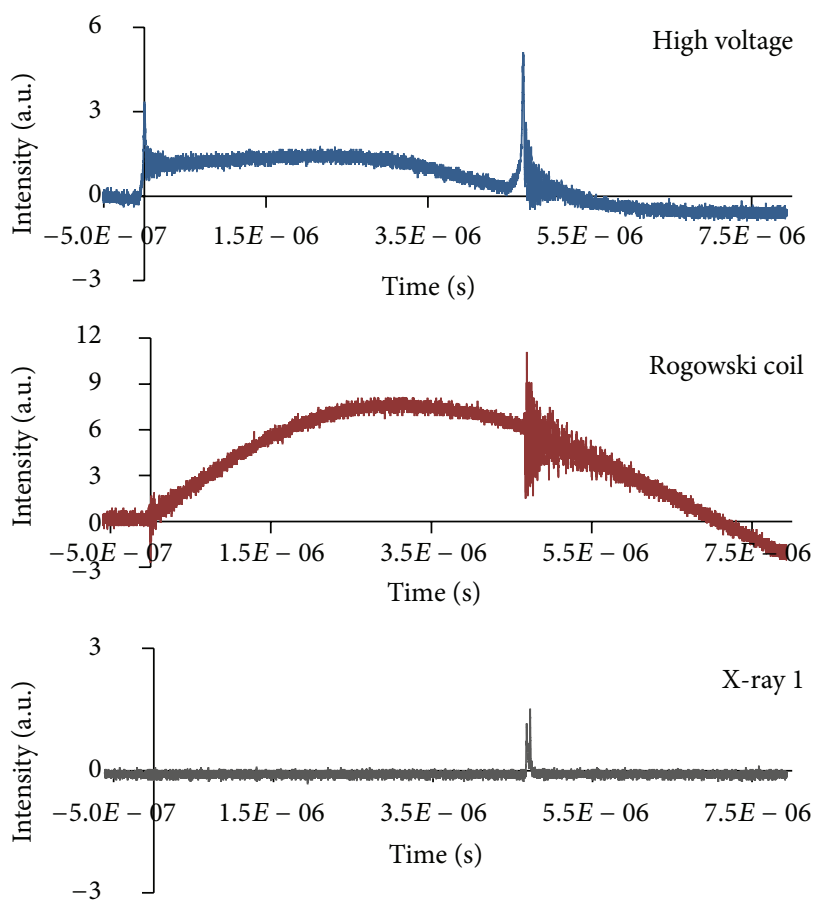

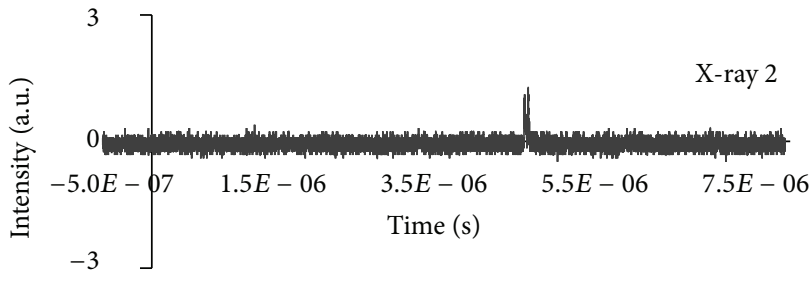

(a)

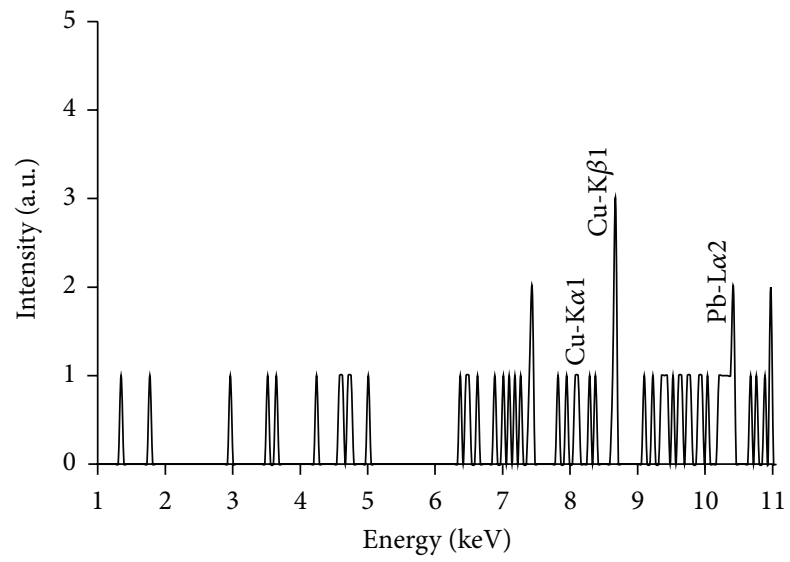

(b)

Figure 9: (a) Temporal evolution of X-ray pulses with Al foil thickness for pressure 1.7 mbar, X-ray $1(23 \mu \mathrm{m}$ aluminized Mylar plus $30 \mu \mathrm{m}$ Al foil) and X-ray $2(23 \mu \mathrm{m}$ aluminized Mylar plus $20 \mu \mathrm{m}$ Al foil) with typical high voltage and Rogowski coil signal. (b) X-ray spectrum: X-ray produced by electron beam-target effect when spectrometer is at top-on position.

abruptly increased and coincided with the dip from the signals of the high-voltage probe signal.

For a shot at pressure of $1.7 \mathrm{mbar}$ and electron beam velocity of $4.6 \times 10^{7} \mathrm{~m} / \mathrm{s}$, the electron beam energy was calculated using the time-of-flight technique from the top part of the hollow anode to the electron collector plate. The calculated average energy of the energetic electron beam was $500 \mathrm{keV}$ at the optimum Argon gas pressure of $1.7 \mathrm{mbar}$. Therefore, the emissions from the energetic electron beam in the low-energy plasma focus device were significant and were caused by instabilities.

To study the low-energy plasma focus device as an electron beam source, we explored the parameters that were dependent on the filling pressure of Argon gas. Given the dependence of the average electron beam current and energy with the filling pressure, electron beam signals were recorded from 0.7 mbar to 2.0 mbar. Figure 11 indicates that the electron beam average current is strongly dependent on the filling pressure.

The maximum average current of the electron beam was $3.19 \mathrm{~A}$ obtained at the optimum pressure of $1.7 \mathrm{mbar}$. At this pressure, the device favors the appropriate discharge dynamics to form a strong pinching [26]. The pinching time occurs near the maximum discharge current, thereby transferring the maximum energy into the plasma. As a result, the emissions from the electron beam were optimal at this pressure, and the maximum average current of the electron beam was achieved. Below the optimum pressure, the beam current decreased because of the weak dynamics of the current sheath at low gas pressures. Increasing the Argon pressure beyond the optimum value decreased the velocity of the current sheath because of the increased sheath mass. Therefore, the focus formation weakened and low electron emissions were produced.

Figures 12 and 13 show the variations in the charge and density of the electron beam with the filling pressure of Argon gas, respectively.

The charge and density of the electron beam were pressure dependent and, respectively, reached their maxima of $0.31 \mu \mathrm{C}$ and $13.5 \times 10^{16} / \mathrm{m}^{3}$ at the optimum pressure of $1.7 \mathrm{mbar}$.

The images of the target before and after being hit by the electron beam in the plasma focus are shown in Figure 14; this 

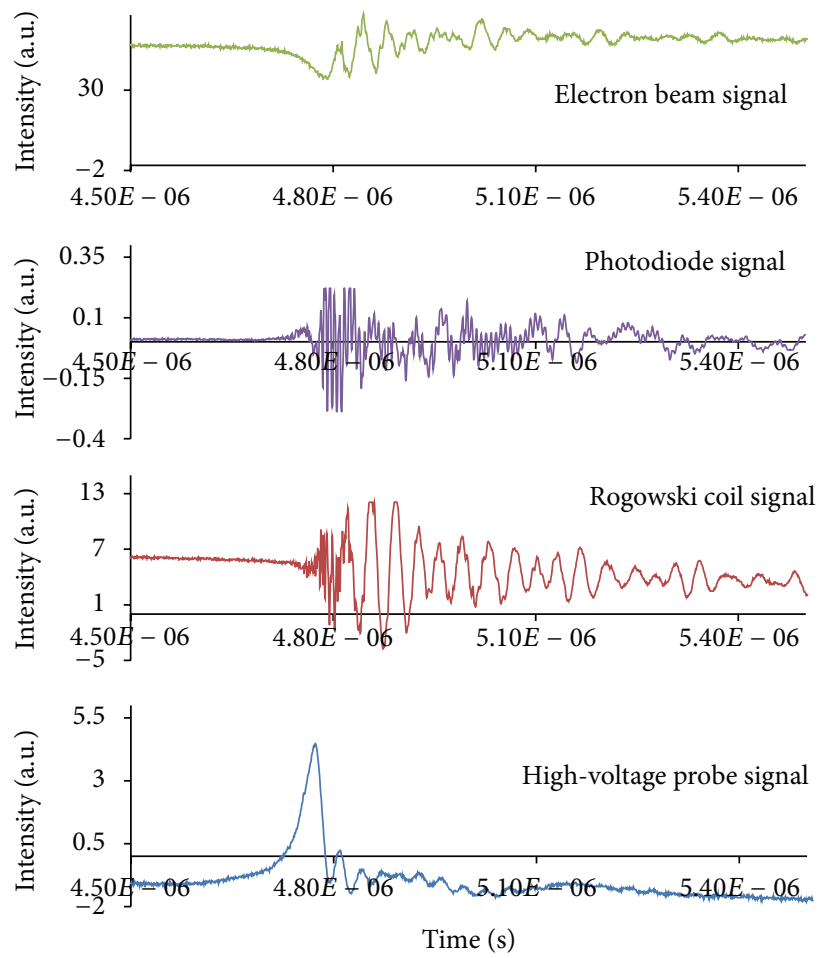

Figure 10: Typical energetic electron beam signal with the signals of photodiode, high-voltage probe, and Rogowski coil (at pressure of 1.7 mbar).

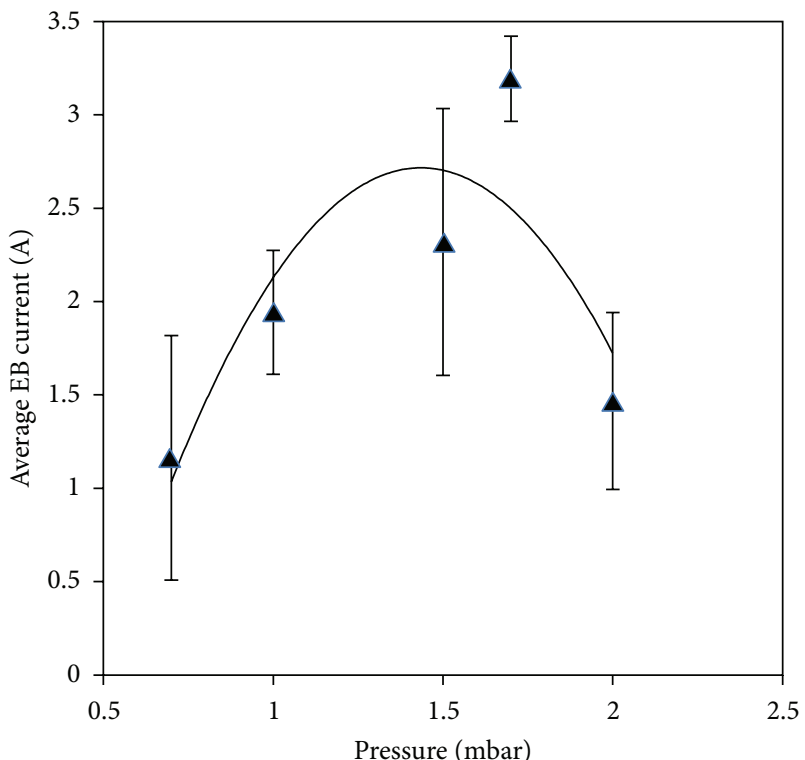

FigURE 11: Variation of average electron beam current versus Argon gas pressure.

interaction is attributed to the bombardment of the energetic electron beam.

The images reveal that when the electron beam hits the lead target (diameter, $1.5 \mathrm{~cm}$; width, $0.35 \mathrm{~cm}$ ), the electron beam is generated from the plasma focus region. Lead is

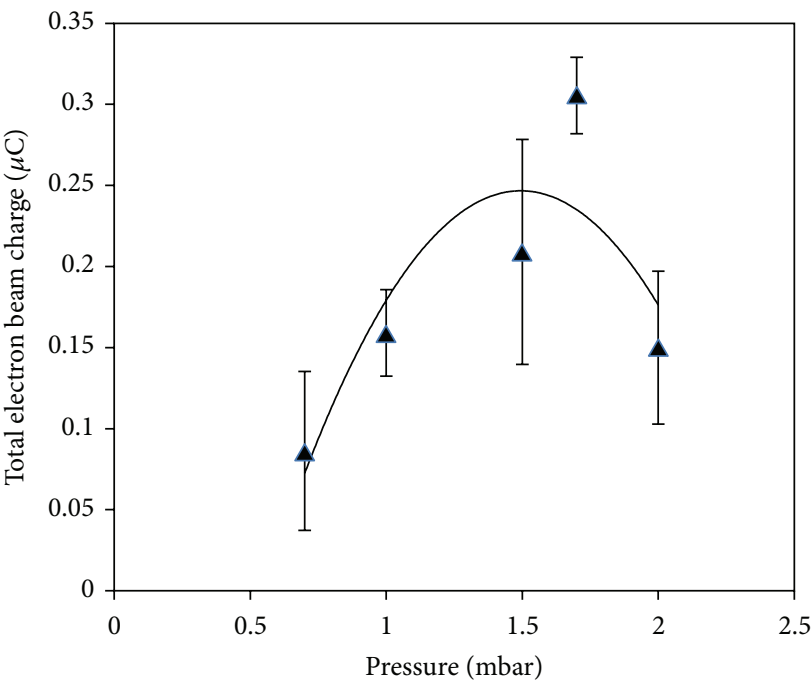

FIgURE 12: Variation of total electron beam charge versus Argon gas pressure.

a feasible material to produce maximum X-ray yield, in contrast to other materials. The marked image in Figure 14(b) is attributed to the interaction of the target with electron beam generated for Argon pressures ranging from $1.5 \mathrm{mbar}$ to 2.0 mbar. The flux of the electron beam significantly affected the material.

The results of X-ray yields and average energetic electron energies were achieved at a pressure range of 1.5-2.0 mbar 


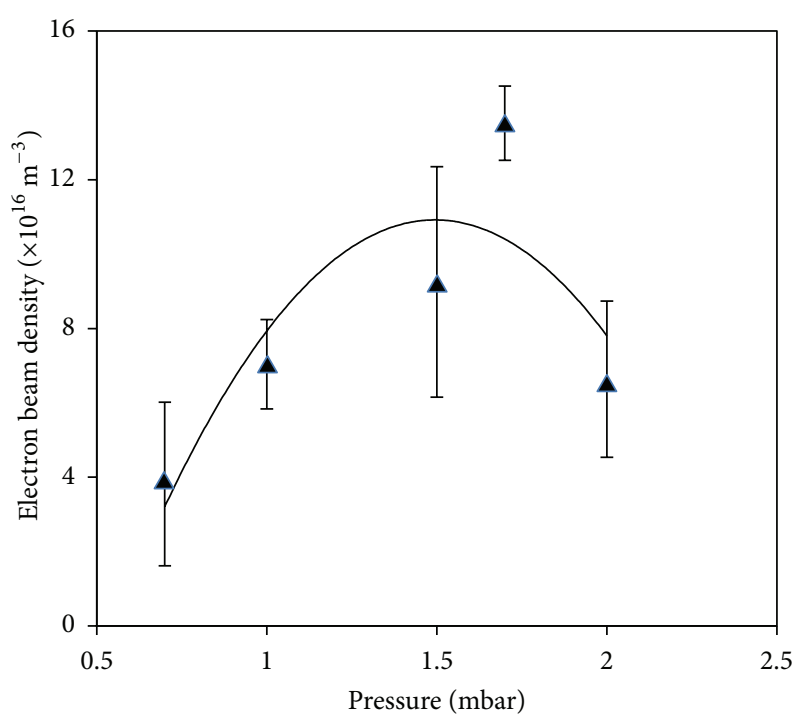

FIGURE 13: Variation of electron beam density versus Argon gas pressure.
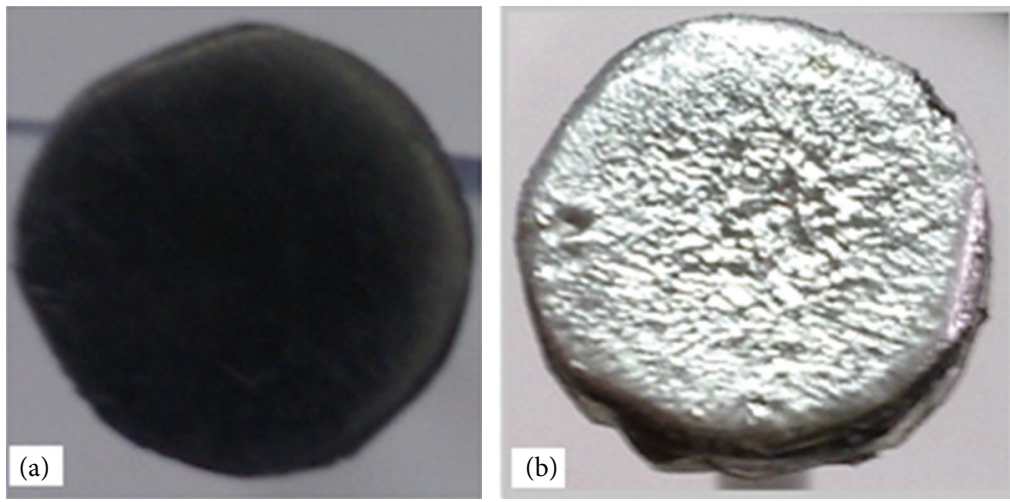

FIGURE 14: Images of the lead target (a) before and (b) after interaction with electron beam in the plasma focus.

because of the strong bombardment of the electron beam. Furthermore, the results from the X-ray spectrometer supported the emissions of the energetic electron beam from the focus region because of instabilities upon hitting the target material. The flux of the electron beam significantly affected the material.

The lower and upper limits of the electron energy differed from the actual values because of the technical limitations of our approach. The proposed technique provided appropriate information of low-energy plasma focus devices as electron beam sources.

\section{Conclusions}

A combination of Faraday cup and photodiode was used to investigate a low-energy plasma focus device $(2.2 \mathrm{~kJ}, 12 \mathrm{kV})$ as an electron beam source at an Argon gas pressure of $1.7 \mathrm{mbar}$. The average electron beam energy was found to be $500 \mathrm{keV}$ with the self-biased Faraday cup. The maximum charge and density of the electron beam were $0.31 \mu \mathrm{C}$ and $13.5 \times 10^{16} / \mathrm{m}^{3}$, respectively. The maximum total X-ray yields were $77 \mathrm{~mJ}$, $47 \mathrm{~mJ}$, and $42 \mathrm{~mJ}$ with corresponding efficiencies of $0.0035 \%$, $0.0021 \%$, and $0.0018 \%$, respectively. The X-ray line spectra revealed $\mathrm{Cu}-\mathrm{K}_{\alpha 1}, \mathrm{Cu}-\mathrm{K}_{\beta 1}$, and $\mathrm{Pb}-\mathrm{L}_{\alpha 2}$ lines with the side-on position of the lead target at $45^{\circ}$; $\mathrm{Cu}-\mathrm{K}_{\beta 1}$ and $\mathrm{Pb}-\mathrm{L}_{\alpha 2}$ lines were observed at the top-on position of the lead target. The high flux of the electron beam could be potentially useful for applications in material sciences.

\section{Conflict of Interests}

The authors declare no conflict of interests regarding the publication of this paper.

\section{Acknowledgments}

The authors acknowledge the experimental and technical support of Mr. Jasbir Singh. This work is supported by the University of Malaya HIR Grant nos. HIR F0043-2014 and RG102-10AFR. 


\section{References}

[1] M. J. Bernstein, "Acceleration mechanism for neutron production in plasma focus and z-pinch discharges," Physics of Fluids, vol. 13, no. 11, pp. 2858-5866, 1970.

[2] J. W. Mather, Methods of Experimental Physics, vol. 9, Academic Press, New York, NY, USA, 1971, edited by H. Griem, R. Lovberg.

[3] W. H. Bostick, V. Nardi, and W. Prior, "X-ray fine structure of dense plasma in a co-axial accelerator," Journal of Plasma Physics, vol. 8, no. 1, pp. 7-20, 1972.

[4] P. Choi, Dense Z-pinches: Proceedings of the 3rd International Conference Held in London, April 1993, vol. 288, AIP, New York, NY, USA, 1994.

[5] L. Jakubowski and M. J. Sadowski, "Hot-spots in Plasma-Focus discharges as intense sources of different radiation pulses," Brazilian Journal of Physics, vol. 32, no. 1, pp. 187-192, 2002.

[6] K. M. Wong, "Study of the electronic structure of individual free-standing Germanium nanodots using spectroscopic scanning capacitance microscopy," Japanese Journal of Applied Physics, vol. 48, no. 8, Article ID 085002, 2009.

[7] W. L. Harries, J. H. Lee, and D. R. McFarland, "Trajectories of high energy electrons in a plasma focus," Plasma Physics, vol. 20, no. 2, pp. 95-106, 1978.

[8] V. Nardi, W. H. Bostick, J. Feugeas, A. Prior, and C. Cortese, "Energy spectra of deuteron and electron beams from focused discharges and optimization criteria," in Proceedings of the 7th International Conference on Plasma Physics and Controlled Nuclear Fusion Research, vol. 2, pp. 143-157, International Atomic Energy Agency, Innsbruck, Austria, 1978.

[9] H. Herold, H. J. Kaeppeler, H. Schmidt et al., in Proceedings of the 12th International Conference on Plasma Physics and Controlled Nuclear Fusion Research, vol. 2, p. 587, Nice, France, 1988.

[10] W. Styger, G. Gerdin, F. Venneri, and J. Mandrekas, "Particle beams generated by a $6-12.5 \mathrm{~kJ}$ dense plasma focus," Nuclear Fusion, vol. 22, no. 9, p. 1161, 1982.

[11] A. Tartari, A. Da Re, F. Mezzetti, E. Angeli, and P. De Chiara, "Feasibility of X-ray interstitial radiosurgery based on plasma focus device," Nuclear Instruments and Methods in Physics Research B: Beam Interactions with Materials and Atoms, vol. 213, pp. 607-610, 2004.

[12] W. Styger, G. Gerdin, F. Venneri, and J. Mandrekas, "Particle beams generated by a $6-12.5 \mathrm{~kJ}$ dense plasma focus," Nuclear Fusion, vol. 22, no. 9, p. 1161, 1982.

[13] A. Tartari, A. Da Re, C. Bonifazzi, and M. Marziani, "Energy spectra measurements of X-ray emission from electron interaction in a dense plasma focus device," Nuclear Instruments and Methods in Physics Research B, vol. 213, pp. 206-209, 2004.

[14] H. Herold, H. J. Kaeppelar, H. Schmidt et al., in Proceedings of the 12th International Conference on Plasma Physics and Controlled Nuclear Fusion Research, vol. 2, p. 587, Nice, France, 1988.

[15] K. Hirano, N. Hisatome, T. Yamamoto, and K. Shimoda, "Imaging Bragg spectrometer for pinched plasma experiments," Review of Scientific Instruments, vol. 65, no. 12, pp. 3761-3765, 1994.

[16] M. Zakaullah, I. Akhtar, A. Waheed, K. Alamgir, A. Z. Shah, and G. Murtaza, "Comparative study of ion, x-ray and neutron emission in a low energy plasma focus," Plasma Sources Science and Technology, vol. 7, no. 2, pp. 206-218, 1998.

[17] P. G. Burkhalter, G. Mehlman, D. A. Newman, M. Krishnan, and R. R. Prasad, "Quantitative X-ray emission from a DPF device,"
Review of Scientific Instruments, vol. 63, no. 10, pp. 5052-5055, 1992.

[18] M. Sadowski, H. Herold, H. Schmidt, and M. Shakhatre, "Filamentary structure of the pinch column in plasma focus discharges," Physics Letters A, vol. 105, no. 3, pp. 117-123, 1984.

[19] F. N. Beg, I. Ross, A. Lorenz, J. F. Worley, A. E. Dangor, and M. G. Haines, "Study of $\mathrm{x}$-ray emission from a table top plasma focus and its application as an x-ray backlighter," Journal of Applied Physics, vol. 88, no. 6, pp. 3225-3230, 2000.

[20] J. R. Smith, C. M. Luo, M. J. Rhee, and R. F. Schneider, "Operation of a plasma focus device as a compact electron accelerator," Physics of Fluids, vol. 28, no. 7, pp. 2305-2307, 1985.

[21] K. Hirano, I. Kaneko, K. Shimoda, and T. Yamamoto, "Method for measuring electron energy distribution in a plasma focus," Japanese Journal of Applied Physics, vol. 29, no. 6, part 1, pp. 1182$1188,1990$.

[22] M. Zakaullah, K. Alamgir, M. Shafiq, M. Sharif, A. Waheed, and G. Murtaza, "Low-energy plasma focus as a tailored X-ray source," Journal of Fusion Energy, vol. 19, pp. 143-157, 2000.

[23] M. Z. Khan, S. L. Yap, and C. S. Wong, “The impact of plasma interference profile (PIP) on argon discharge in plasma focus device," International Journal of Physical Sciences, vol. 8, no. 8, pp. 286-294, 2013.

[24] M. Z. Khan, S. L. Yap, M. A. Khan, and M. Zakaullah, "Effect of cathode designs on radiation emission of compact diode (CD) device," Journal of Fusion Energy, vol. 32, no. 1, pp. 34-41, 2013.

[25] M. Z. Khan, S. L. Yap, and C. S. Wong, "Estimation of electron temperature and radiation emission of a low energy $(2.2 \mathrm{~kJ})$ plasma focus device," Indian Journal of Physics, vol. 88, no. 1, pp. 97-102, 2014.

[26] H. Bhuyan, S. R. Mohanty, N. K. Neog, S. Bujarbarua, and R. K. Rout, "Magnetic probe measurements of current sheet dynamics in a coaxial plasma accelerator," Measurement Science and Technology, vol. 14, no. 10, pp. 1769-1776, 2003. 

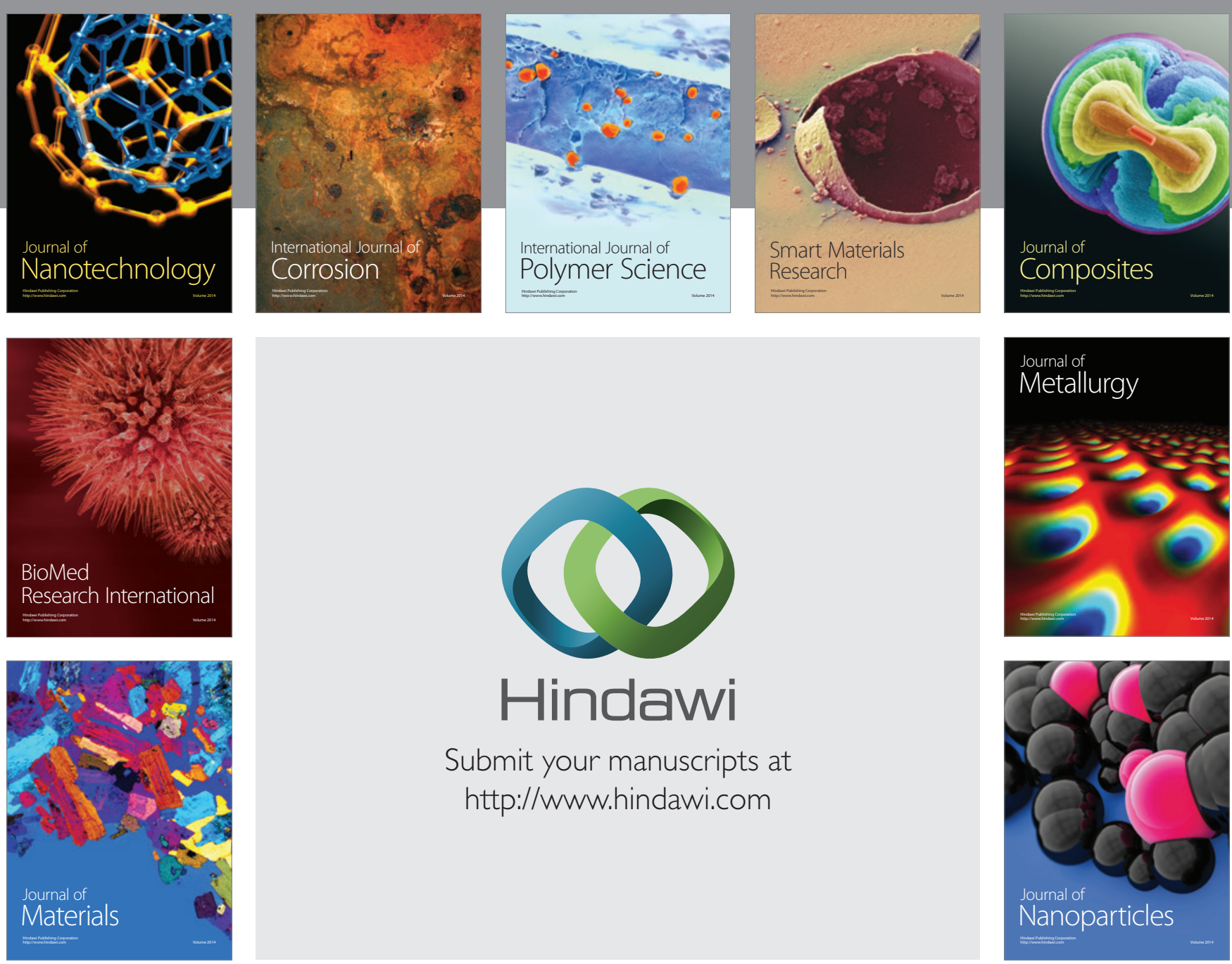

Submit your manuscripts at http://www.hindawi.com
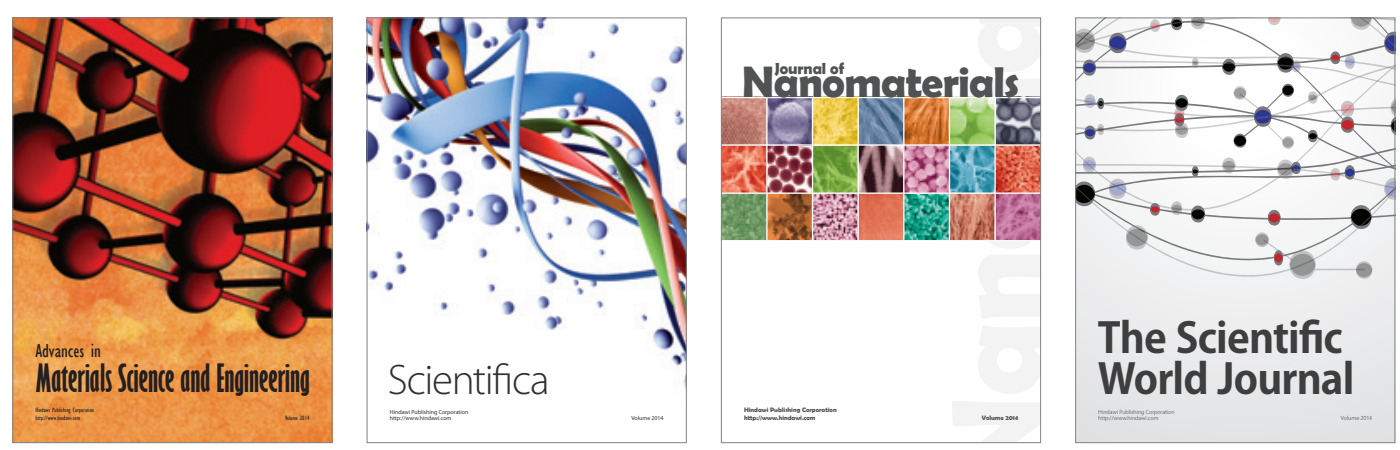

\section{The Scientific World Journal}
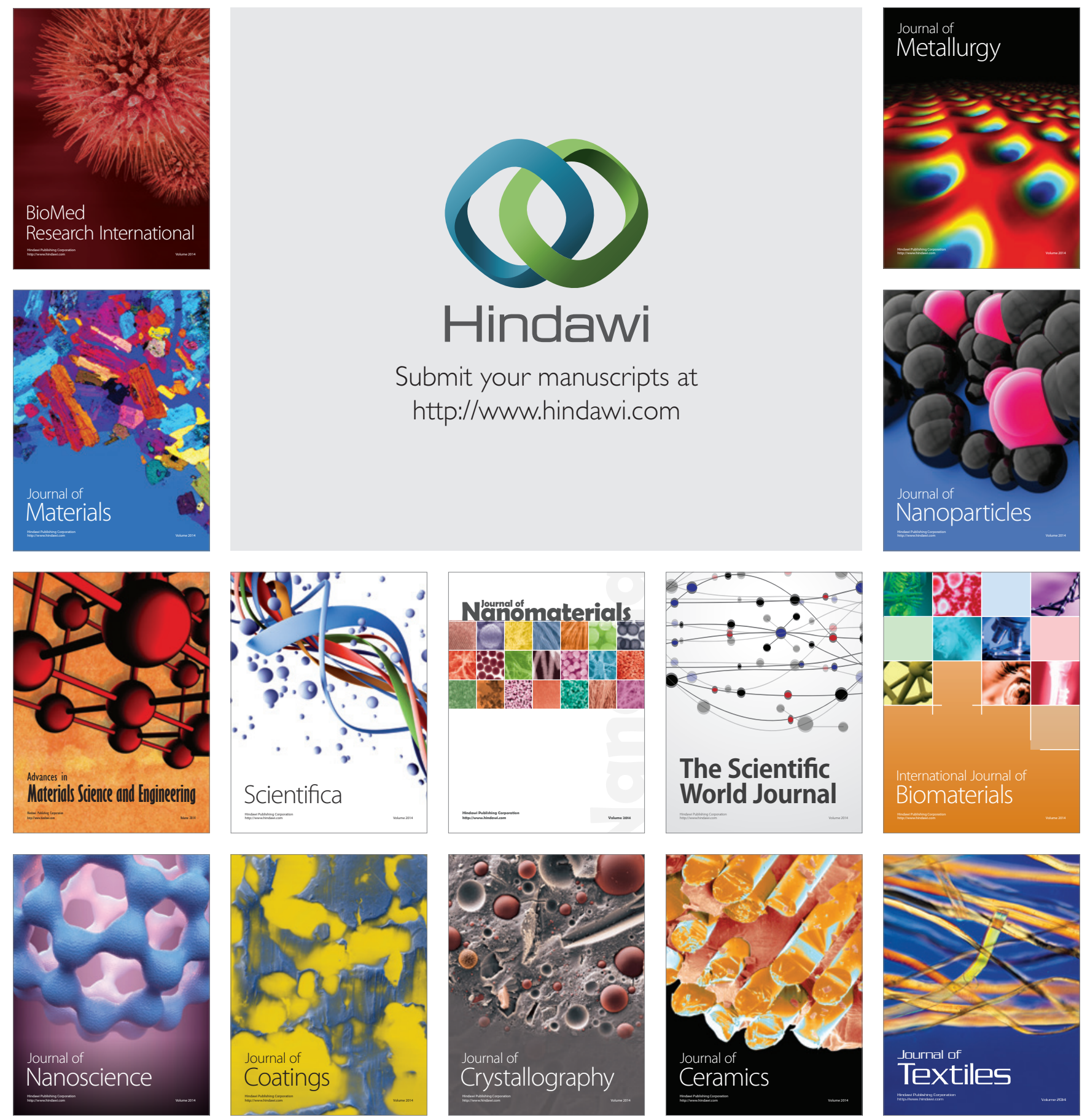